\title{
Spinoff dynamics beyond clusters: pre-entry experience and firm survival in peripheral regions
}

\author{
Antoine Habersetzer \\ Institute of Geography, Centre for Regional Economic Development, University of Bern, \\ Switzerland
}

Address: Institute of Geography, Hallerstrasse 12, 3012 Bern, Switzerland,

E-Mail address: antoine.habersetzer@giub.unibe.ch

Draft version: Please do not cite this version of the manuscript!

For information on the published article, please contact the author.

\begin{abstract}
:
This paper investigates local spinoff dynamics in manufacturing industries in peripheral areas. It focuses on the question whether local inheritance of competences and routines from parent firm to spinoff is also relevant for firm survival in peripheral areas. The analysis is based on a unique dataset, tracking all manufacturing firms at five observation points during the time span of 1980-2004 in two case study regions in Switzerland. The results show that the local inheritance of capabilities gives spinoffs a competitive advantage in peripheral regions as well. Further, the findings suggest that spinoff dynamics differ between different types of peripheral regions, depending on their varying local economic conditions. Finally, spinoff dynamics in the periphery might be characterized by a stronger hostility of larger parent firms towards spinoffs. This research adds a distinct peripheral perspective to the entrepreneurial heritage literature and advocates for a more nuanced discussion on spinoff dynamics in varying geographical settings.
\end{abstract}

Keywords: entrepreneurship, evolutionary economic geography, manufacturing industries, peripheral regions, spinoffs, Switzerland

\section{Acknowledgement}

This work was supported by the Swiss National Science Foundation under Grant number 146436. I would like to thank Heike Mayer, Ron Boschma and Martin Warland for their constructive comments. Any errors or omissions remain, of course, my responsibility. 


\section{Introduction}

Entrepreneurship is not only a central driver for economic change (Schumpeter 1934), but also for regional development (Shane 2003; Malecki 1994; Beugelsdijk 2007). Entrepreneurial agency, in the form of new firm formation leads to a constant modification of a regional firm population. Regional economies with a dynamic firm population are better able to preserve or even strengthen their competitiveness (Frenken, Cefis, and Stam 2015). When classifying regions based on the competitiveness of their regional economy, a dichotomous differentiation between core and peripheral regions is often used. It is stated that economic actors, such as firms and entrepreneurs, located in metropolitan areas or clusters are more entrepreneurial and competitive because of various beneficial agglomeration externalities and abundant entrepreneurial opportunities (Stuart and Sorenson 2003; Sorenson and Audia 2000). For firms in peripheral areas however, it is habitually assumed that these are generally less competitive because of, for instance, a low level of clustering, limited R\&D activities, few innovation-supporting organizations, and limited knowledge transfer networks (Tödtling and Trippl 2005). While it is certainly true that peripheral areas are characterized by several structural and relational characteristics potentially reducing entrepreneurial agency and firm competitiveness, this narrative underestimates the importance of firm heterogeneity (Van Oort et al. 2012; Buercher, Habersetzer, and Mayer 2016). The competitiveness of firms strongly differs based on their specific history and routines, as well as on the entrepreneurial capabilities of their founders and managers (Renski 2015). The empirical evidence of successful firms located outside of core regions (North and Smallbone 2000a) raises the question, how one can explain the competitiveness of these firms.

This paper argues that the heritage theory is well suited to explain varying firm competitiveness in peripheral areas and tests this by analysing local spinoff dynamics in peripheral regions. Spinoffs are defined as companies founded by entrepreneurs with prior work experience in the industry where the new company is active in. This definition thus differs from the corporate spinoff, which describes newly created firms that are still part of the mother corporation. It should also not be confounded with university spinoffs, comprising companies that are founded by university graduates, which generally have no work experience in the focal industry.

The heritage theory (Buenstorf and Klepper 2009) states that successful firm routines are diffused within a regional firm population by spinoff processes (Klepper 2009; Golman and Klepper 2013; Dahl and Sorenson 2013). However, the existing empirical literature on routine inheritance either concentrates on industry or firm characteristics (and thus omits spatial aspects), or focuses on regions with accentuated clustering dynamics in a specific industry (Boschma 2015). From an empirical perspective, it is thus unclear if inheritance processes also occur in peripheral regions. Only very few case studies exist that qualitatively analyse the spinoff processes related to exceptional parent firms (Benneworth 2004; Mayer 2011). However, no quantitative study exist so far examining spinoff processes in peripheral areas and identifying differences in inheritance effects between different peripheral regions.

This study addresses these issues by evaluating the influence of different degrees of pre-entry experience on the survival of firms in the periphery. Pre-entry experience is identified by management positions firm founders held before they found their companies. Degrees of pre- 
entry experience comprise whether founders gathered management experience at all, in which industry they gathered it, and what characteristics the prior employer has. The paper has three main objectives. First, the heritage theory in the context of peripheral regional economies is discussed. It is argued that spinoff processes are theoretically also possible in peripheral regions and that the heritage theory might be useful to better understand competitiveness of firms in peripheral areas. The second objective consists in empirically analysing the influence of the founders' pre-entry experience on the survival of new firms in two case study region. More specifically, the 'Toggenburg' and the 'Rheintal', two peripheral regions in eastern Switzerland are examined. These two regions were picked because they are both peripheral, but show some interesting diverging developments. The analysis is based on a unique dataset, covering five observation points during the time period from 1980 to 2004 and comprising 933 manufacturing firms and their management, more specifically, all persons having signature rights. The results show that spinoff effects are indeed also present in peripheral regional economies. Third, I focus on differences in local spinoff dynamics between the two case study regions. As the case study regions show quite different development paths, it is expected that spinoff dynamics differ as well.

In order to address these objectives, a change of perspective is necessary. Contrary to most heritage studies, this paper does not try to explain clustering of a specific industry in a region by portraying local inheritance processes. Rather, it analyses local spinoff dynamics in all manufacturing sectors in the two case study regions. Thus, not the heritage of a specific industry is of interest, but rather the entrepreneurial heritage of a regional economy. At the core of the investigation stands the question if local pre-entry experience of firms located in regions without major clustering processes raises their probability of survival. Ultimately, I will discuss what specific characteristics inheritance effects in peripheral regions have, and what conclusions can be withdrawn from the results with regard to regional development in peripheral regions. Based on this reasoning, the paper is structured as follows. In section two, I will discuss the heritage theory with a special emphasis on its applicability on peripheral regions. Based on this theoretical discussion, I deduce the research questions and hypotheses. Section three contains a description of the case study regions, the data source and the employed methods. In section four, I present the results from the logistic regression analysis. In section five, I discuss the most important results concerning local spinoff dynamics and regional development in peripheral areas.

\section{Inheritance effects in peripheral firm populations}

Entrepreneurship is an important factor for regional development (Acs and Storey 2004; Fritsch and Mueller 2004; Beugelsdijk 2007). Entrepreneurial agency, often measured with new business formation, varies significantly between different regions (Armington and Acs 2002). As vibrant entrepreneurial dynamics are generally attributed to large and diverse urban areas with specialized pools of workers, innovative industries, and successful knowledge exchange mechanisms, it is concluded that entrepreneurship is first and foremost a phenomenon of metropolitan areas and large industry clusters (Glaeser, Rosenthal, and Strange 2010; Audretsch et al. 2012). Based on the characteristics of regional economies, it is common to differentiate between core and peripheral regions. In this paper, we understand peripheral regions as being outside of metropolitan areas (Lagendijk and Lorentzen 2007; Freire-Gibb and Nielsen 2014) ${ }^{1}$. 
In this line of thought firms in peripheral regions are generally seen as less entrepreneurial and competitive because of the distance to important markets, information sources, and skilled workers (Malecki 2003), less effective regional innovation systems (Tödtling and Trippl 2005; Lengauer and Tödtling 2010; Isaksen 2015). However, these approaches focusing on agglomeration externalities often do not take the heterogeneity of firms and entrepreneurs into account (Shaver and Flyer 2000; Rigby and Brown 2015). While many firms in peripheral areas may indeed concentrate on producing low-tech products and serving local markets, some firms might show exceptional entrepreneurial agency and growth ambitions $^{2}$. Freire-Gibb and Nielsen $(2014 ; 2010)$ analysed differences between urban and rural areas with regard to the profiles of entrepreneurs, the likelihood of becoming an entrepreneur and the likelihood of survival of new firms. For all three aspects, they found no significant differences between rural and urban entrepreneurs.

There is thus increasing evidence entrepreneurship can significantly contribute to the development of peripheral regions (Baumgartner, Pütz, and Seidl 2013; Stephens and Partridge 2011; Anderson 2000). The question arises to what extent entrepreneurial firms have to rely on the local economic environment. For branch plants from multinational enterprises, one could argue that they already possess enough competences and are well embedded in the company's network, so they do not have to rely on the local economic environment. Their competitiveness is thus to a little extent related to regional economic conditions. This is different for newly founded firms in peripheral regions, as they more often rely on support and assistance from other local firms and organizations (North and Smallbone 2000b). From an agglomeration externalities perspective, one would argue that peripheral entrepreneurs are less able to identify and exploit market opportunities because of the distance to markets and customers, missing R\&D institutions, and less effective knowledge spillover dynamics (Freire-Gibb and Nielsen 2014).

Despite these potentially negative economic conditions, I argue that newly founded firms in peripheral areas can profit from their local economic environment in another way, that is, by the experience the founders accumulated by working at other local firms. This pre-entry experience can also be called entrepreneurial heritage. The heritage theory relates the spatial clustering of an industry to regional spinoff dynamics. Based on the principles of evolutionary economics (Nelson and Winter 1982) and evolutionary economic geography (Boschma and Frenken 2006; Essletzbichler and Rigby 2007; Martin and Sunley 2015), the heritage theory puts entries and exits of firms, and the capabilities they possess, in the centre of their analysis of regional industry clusters. The fundamental assumption of the heritage theory is that a regional firm population of a specific industry shares a certain set of firm routines, if they are related via parent-spinoff relationships. During their work experience entrepreneurs learned industry specific organizational routines, a type of tacit knowledge that can only be acquired through on-the-job-learning. Consequently, as Klepper $(2011,145)$ states it, 'incumbent firms are natural training grounds for the next generation of entrepreneurs in an industry'. This entrepreneurial heritage will influence entrepreneurs when they found a new firm. The deep knowledge about the industry gives firms with pre-entry experience (spinoffs), a significant advantage in comparison to de novo entrants (firms without any pre-entry experience), or experienced entrepreneurs (firms with pre-entry experience, but not in the specific industry in which the new firm is active) (Klepper 2001). 
The novelty of the heritage theory is that firm competitiveness can be explained without referring to agglomeration externalities, but solely by accounting for the pre-entry experience of the founders (Buenstorf and Klepper 2009). In other words, the positive influence of the regional environment on entrepreneurship does not solely consist in offering positive agglomeration externalities, but also in providing a reservoir of competences, 'stored' in local firms, and 'diffused' in the course of spinoff dynamics. Consequently, agglomeration externalities are not a prerequisite for firm competitiveness and regional growth. This conclusion is especially relevant for peripheral regions. Since these regions are characterized by low clustering dynamics, the competitiveness of peripheral firms can hardly be explained with the benefits of agglomeration externalities alone. As pointed out above, a conclusion commonly found in the literature is thus to assert all firms in peripheral areas with limited competitiveness. The heritage theory can give an alternative explanation for the varying competitiveness of firms in peripheral areas by specifically considering the pre-entry experience of their founders. In this line of thought, the routines of existing local firms and the latent entrepreneurial skills of employees can be seen as a potential for endogenous regional development, if newly founded firms with local pre-entry experience show a higher survival chance as compared to firms without it. Thus, the core question of this study is, if local pre-entry experience of firm founders in the periphery positively affects the survival chances of their venture.

However, existing contributions focusing on spinoff dynamics almost exclusively analysed inheritance effects within industries that are characterized by exceptional inheritance processes and a highly accentuated spatial clustering (Klepper 2001), such as the automobile industry in the United States in Detroit (Klepper 2002; Klepper 2007) and in Great Britain in the Coventry-Birmingham area (Boschma and Wenting 2007), the U.S. tire industry in Akron, Ohio (Buenstorf and Klepper 2010), the North Jutland high-tech cluster in Denmark (Dahl, Pedersen, and Dalum 2003), the Dutch publishing industry (Heebels and Boschma 2011) in Amsterdam, or the semiconductor industry in silicon valley (Klepper 2010; Cheyre, Kowalski, and Veloso 2015), to name a few. In these empirical investigations, the heritage approach has been used to explain the subsequent clustering of the industry. Even though these contributions clearly show the importance of spinoff dynamics for explaining the survival probability of firms and the spatial clustering of an industry, they do not answer the question to what extent heritage effects are a phenomenon restricted to large clusters of specific industries, or if they also influence the survival of firms in areas without significant clustering dynamics.

A few studies investigate spinoff dynamics not for one specific industry, but for distinct spatial entities. Andersson and Klepper (2013) assessed inheritance effects for all industries in Sweden, and compared the results with studies from Denmark, Brazil, Norway and the US. They conclude that spinoff dynamics show quite similar results across different national frameworks, indicating that inheritance effects are not confined to industries with strong clustering dynamics. However, they do not account for differences at the regional level. Dahl and Sorenson (2012) analysed the combined effect of regional and industry experience on the performance of Danish startups. They find that both types of experience have a positive effect on firm performance, and conclude that not only human capital (in the form of industrial preentry experience), but also social capital (in the form of regional experience) are important for 
the success of an entrepreneurial venture. The here presented study follows this logic by analysing not a single industry, but tries to assess the impact of local pre-entry experience across the entire breadth of manufacturing sectors. Consequently, the focus is not on the accumulated heritage of a specific industry, but on the spinoff dynamics in general within a regional firm population, termed as regional entrepreneurial heritage.

\section{Hypotheses:}

Following the review of the literature on the heritage theory, the following hypotheses can be drawn. As argued before, the heritage theory is well suited to be applied to peripheral regions, since it does not require agglomeration externalities as a prerequisite for firm competitiveness. Peripheral regions are an interesting case in that respect. On the one hand, positive localization effects are supposed to be limited due to the small size of local firm populations. Nonetheless, localization economies, measured by the size of the local firm population of a specific industry, should exist and have a positive effect on firm survival, because the small firm population should keep the negative effects of industrial concentration (mainly high costs for input factors such as land and labour costs) low.

Hypothesis 1: The size of the industry-specific local firm population and the share of industryspecific medium-sized and large firms have a positive effect on the survival of new firms.

Beside the positive effect of localization externalities, I especially expect a positive effect of pre-entry experience on firm survival. In line with the heritage theory, one can assume that the successful routines in a peripheral region emerge either by chance, or are 'imported' by a performing firm setting up a branch plant in the region (Mayer 2011). These firms function as a 'reservoir of competences' and effective training grounds for employees. If these employees start their own firm in the same industry, they can rely on what they learned during their previous employment and, at least to a certain extent, transfer the routines of the parent firm to their newly founded company. Consequently, also in peripheral areas, one expects local spinoffs to show a higher chance of survival, as compared to other types of entry.

Hypothesis 2: Local spinoffs in peripheral regions show a higher survival chance as compared to de-novo entrants and experienced entrepreneurs.

Within this narrative, firm heterogeneity, in the form of varying chances of survival, can be explained with different types of pre-entry experiences firm founders possess. Yet, not only the type, but also the quality of pre-entry experience should have repercussion on firm survival. Theoretically, the set of routines a firm possesses is idiosyncratic (Frenken and Boschma 2007) and routine quality will strongly differ between firms (Maskell 2001). Again, in line with the heritage theory, the routines experienced entrepreneurs and spinoffs acquire should differ based on the performance of the parent firm, as these hold more successful routines and offer a better learning environment for latent entrepreneurs. Consequently, one expects that firms with local pre-entry experience from surviving parents show a higher survival chance as compared to firm without the pre-entry experience from surviving parents.

Hypothesis 3: Firms in peripheral regions with local pre-entry experience from a surviving parent show a higher survival chance as compared to firms with local pre-entry experience from only non-surviving parents. 
Not only surviving parents, but also larger parents should possess superior routines. Especially larger manufacturing firms in peripheral regions are highly dependent on their inhouse competences, as localization effects and local knowledge spillover are rather limited. Also, these firms most likely cannot limit their economic activity to the rather small local market, but have to be active on extra-regional markets. In order to be competitive on these distant markets, superior routines are necessary. Consequently, one can expect that pre-entry experience from medium sized and large companies is superior to pre-entry experience acquired from small firms.

Hypothesis 4: Firms in peripheral regions with local pre-entry experience from medium-sized or large parents show a higher survival chance as compared to firms with only small parents.

As outlined in the next chapter, the Rheintal showed a more dynamic industrial development in the last 40 years as compared to the Toggenburg. One can thus expect, that spinoff dynamics differ between both regions. More specifically, it is anticipated that the specific characteristics of the parent firm might have a stronger impact on the survival of progeny in the Toggenburg than in the Rheintal. As regional entrepreneurial heritage in the Rheintal is more dynamic and less characterized by few dominating firms and entrepreneurial personalities, the specific characteristics of the parent firm should be less important in the Rheintal. In this case, the simple fact of having local pre-entry experience might be more important than where exactly the experience was gathered. In the Toggenburg, however, the survival chance of progeny might heavily depend on the specific pre-entry experience new firms build on. With a weaker developed regional entrepreneurial heritage than in the Rheintal, successful routines might be stronger confined to a few firms in the Toggenburg.

Hypothesis 5: The positive effect of surviving parents on the survival of progeny is larger in the Toggenburg in comparison to the Rheintal.

Hypothesis 6: The positive effect of larger parents on the survival of progeny is larger in the Toggenburg in comparison to the Rheintal.

In a first step, the first five hypotheses will be tested with cox regression models comprising firms from both regions. In a second step, the last two hypotheses will be tested running separate regression models for each region.

\section{Case Study Regions, Data and Methods}

Case Study Regions

The empirical analysis is based on the population of manufacturing firms of two Swiss peripheral regions, the Toggenburg and the Rheintal, both located in eastern Switzerland. The reasoning behind choosing these regions is threefold: First, they are both located in the Kanton of St. Gallen. Thus, they dispose of the same legal and a comparable macro-economic framework. Second, both regions are, formally speaking, peripheral, as they are located outside of the metropolitan regions of Switzerland (Schuler et al. 2005). Also concerning their size in terms of population ${ }^{3}$ and manufacturing firms ${ }^{4}$ they are clearly not metropolitan, but characterized by small towns. The largest towns in the Rheintal and the Toggenburg have 11,000, and 13,000 inhabitants respectively. Further, due to the geographical characteristics of both regions, spillover effects from neighbouring regions are limited. The Toggenburg 
consists of two valleys tightly confined by ranges of mountains and hills to its west, east and south. Close range economic interaction with neighbouring regions is largely limited to its north end, where the Toggenburg connects to the Swiss mainland. The Rheintal region is confined by a range of hills to the west and the Swiss-Austrian border to the east. This limits the time-efficient access to the Swiss mainland to the north end of the valley, where the Rhein River flows into the Lake of Constance.

[Insert figure 1 around here]

Third, even if both regions are peripheral and share a comparable macro-economic framework, their industrial structure and development shows quite some differences, making a comparison between the two regions interesting. The regional economy of the Rheintal has been more successful in dealing with the deindustrialization process, starting in the 1970s. While the Toggenburg had more employment in the secondary sector in $1970-19,700$ employees in the Toggenburg versus 16,700 in the Rheintal - the latter now has more employed workers in the secondary sector - around 13,500 in the Rheintal versus 12,700 in the Toggenburg. Population growth between 1970 and 2012, as a general proxy for medium and long term economic development is slightly higher in the Rheintal $(+22 \%)$ than in the Toggenburg $(+16 \%)$. Also, the Rheintal shows more dynamic entrepreneurial culture in the secondary sector with almost twice as many firm formations in 2011 (31) as compared to the Toggenburg (17). Finally, the taxpaying ability index, as a proxy for the overall wealth of the population, is roughly $20 \%$ higher in the Rheintal than in the Toggenburg. Based on these diverging performance indicators, one can conclude that the regional manufacturing economy of the Rheintal is more dynamic and successful in comparison to the Toggenburg 5 . Based on those diverging aspects, one can thus expect that heritage effects might differ between the regions. This is analysed in the following by comparing the populations of manufacturing firms in both regions.

\section{Data}

To analyse spinoff dynamics a historical dataset is necessary. This data was retrieved from the 'Schweizer Ragionenbuecher', a yearly issued compilation of every officially registered firm, respectively establishment ${ }^{6}$ in Switzerland, sorted by municipalities. The first issue was published in 1894, the last appeared in 2004. From these books, information on a firm's location and field of activity (industrial branch), as well as every person that has the signatory power in the name of the company, can be withdrawn. The fact that I only have information on persons with signature right has two major implications for the empirical analysis of spinoff dynamics. First, the pre-entry experience that can be measured with this data source does not contain every work experience founders have gathered throughout their complete career. It is rather confined to the work experience where the individual has the explicit signature right. This of course limits the pre-entry experience I am able to identify, but has one major advantage. It confines the relevant pre-entry experience to those employments that are supposed to have the highest impact on the learning of firm routines. The signature right will not be granted to anyone, but to those persons having the capacity to take informed decisions in the name of the company. These, in consequence, are the persons having a deeper knowledge and understanding of the routines of their firms (Phillips 2002), as they have to understand the consequences of their decisions for the company. One can thus assume that 
having the signature right can be understood as having gained deep and valuable industryspecific pre-entry experience. Second, it concerns the identified founders of a company. It is important to note, that the database does not contain direct information on the firm founders, but on every person with the legal right to sign in the name of the company. In most cases, the persons with signature rights during the founding period of a firm are also its founders (Dahl and Reichstein 2007). Depending on the legal form of the company, this could be the owner in the case of sole proprietorship, but also board members of joint stock companies or members of limited liability companies. Thus, their knowledge is especially valuable when forming the routines of newly founded firms (Klepper 2001; Agarwal et al. 2004). Further, these persons are responsible for the organizational structure of the new firm, as they hold the top-hierarchy position and the signature right. They are thus the central decision makers in the company and the pivotal persons during the founding process (Dahl and Reichstein 2007). For simplification, these persons will be generally referred to as management.

For the two case study regions respectively, information on the complete population of manufacturing firms (excluding food and beverage producers in order to exclude firms that might be primarily active in the agricultural sector) where collected for five years: 1980, $1986,1992,1998,2004$. The format of the books made it necessary to digitalize the data by hand, which engendered a limited number of time observations. The period from 1980 to 2004 was chosen, because it brings about incremental, but fundamental changes for the manufacturing industry in Switzerland concerning the macroeconomic framework and the general business strategies. First, deindustrialization processes in Switzerland started in the 1970s and impacted manufacturing firms especially in the 1980s and 1990s. Second, the 1980s mark the beginning of modern globalization dynamics with important repercussion on production organization, distribution, market competition and changes in legal frameworks (Müller 2012). It is thus a well suited sample period for analysing the determinants of firm survival, because times of change and struggle lead to a more pronounced selection of successful routines through firm entry and exit.

In order to reliably identify and track a firm through the different observation periods, a unique firm identifier was created, based on firm characteristics that are relatively constant throughout the firm's history. These are (1) the location, (2) the industry classification, and (3) the founding date of the firm. If in one sampling period one firm identifier was attributed to two different firms, the identifier was modified manually. In a second step, additional firm characteristics were used to check if identifiers are consistent over several observations. If for two or more different firm entries in different time periods, two out of the three primary identification characteristics were similar, and other additional characteristics were similar as well, it was checked if the different entries were indeed different firms, or if some sort of data error lead to the false construction of two different firm identifiers. This leads to the identification of 2052 single firms. The same method was applied to correctly identify and track managers in the database. Unique person identifiers were created based on first name, last name, place of residence, and place of citizenship ${ }^{7}$ of individuals. Double counts were manually checked for consistency. 6616 single managers were identified.

Methods 
A semi-parametric hazard model is used to determine to what extent the pre-entry experience of firm founders influences the survival probability of new firms. More specifically a Cox proportional hazard regression model of the form

$$
h(t, X)-h_{0}(t) \operatorname{\propto xp}\left(\sum_{i=1}^{F} B_{i} X_{t}\right)
$$

is employed, where $h(t, X)$ is the hazard ratio, $h_{e}(t)$ is the baseline hazard function, and $X=\left(X_{1}, X_{2, \ldots,} X_{p}\right)$ are the covariates.

For the regression model, only firms founded between 1981 and 1999 are included in order to be able to deduce information on the founders' pre-entry experience from the dataset. Since the dataset only consists of few discrete observation points, the Efron approximation method to handle tied failures is used. For all models, the proportional hazard assumption was tested using the Schoenfeld residuals test. All models returned clearly insignificant results for the global and individual variables tests, indicating that there is no evidence to contradict the proportional hazard assumption. The results are presented in models 1-8 in tables 2 and 3.

Firm survival: If a firm does not encounter a failure event until the last observation period (Shaver and Flyer 2000), this is understood as the survival of the firm ${ }^{8}$. However, the disappearing of a firm from the database does not necessarily mean that it stops to exist, it could also change its location outside of the case study region. Since the goal of this paper is to investigate regional entrepreneurial heritage, understood as the pool of routines of local firms, an exit of a firm or production site from the database can be understood as the loss of this specific firm's routines and competences for the regional entrepreneurial heritage, independent of the question if the firm indeed stops to exist or if it is simply moving its location to another region. Another possibility for firm exits is the reorganization of the firm, for instance a re-foundation with a different legal form, or the founding of a corporate holding. This would be classified in the database as an exit with a subsequent founding of a new firm with pre-entry experience (under the condition that at least one manager from the former firm is active in the new firm(s). In this case, regional entrepreneurial heritage is not lost, but transferred to a new firm via routine inheritance. Even more, this can be interpreted as a positive form of entrepreneurial agency, as the firm population adapts to changing economic conditions.

Independent variables of interest: Pre-entry experience, parent survival, and firm size distribution across industries are the primary independent variables of interest. If a firm identifier first appears in the dataset, it is screened if and where the managers of the new firm were working in the previous period of observation. Again, it is important to emphasize that this study, comparable to Phillips (2002), is only covering local pre-entry experience, and not every pre-entry experience firm founders might have gathered. When discussing endogenous regional development potentials, it is especially interesting to analyse to what extent the preentry experience entrepreneurs gathered locally has an impact on firm survival. Also, as outlined before, pre-entry experience is confined to those employments where the individual had the signature right. In line with most heritage papers (see f.i. Dahl, Pedersen, and Dalum 2003; Klepper 2007), I differentiate four types of entering firms. First, newly founded firms 
with management for which no information on past management experience in local firms is present in the database are defined as de novo entrants (variable: de novo). Second, I term firms entering the case study regions, but which are not newly founded, as diversifiers (diversifier). The founding year indicates that these firms existed before they first appeared in the dataset. This can have two reasons: Either, the firm was already present in the region, but changed its main field of activity and is thus understood as a new entrant in the respective industry, in other words, an industrial diversifier. Or, the firm was founded outside of the case study regions and then moved its location to, or establishes a new site in one of the case study regions, which can be termed as spatial diversifier. The structure of the data source does not allow us to empirically differentiate between the two types of diversifiers. Third, new firms with at least one manager that had a management position in another local firm, but in a different industry class ${ }^{9}$ are classified as experienced entrepreneurs (experienced). Finally, firms with at least one manager with management experience in another local firm of the same industry class are denominated as spinoffs (spinoff). In a second step, experienced entrepreneurs and spinoffs are further differentiated based on the characteristics of their parent firms. For every experienced entrepreneur and spinoff, I check if at least one parent survived and if at least one parent firm is a medium sized or large company. The distribution of different entry types is reported in table 1. Finally, the size of the (2-digit) industry-specific regional firm population (Industry size) and the firm size distribution within a regional industry is taken into account. The latter variable represents the percentage share of medium sized and large firms within a two-digit industry classification over the observed time period (share larger firms).

\section{[Insert Table 1 around here]}

Control variables: I include three control variables in the models to account for other firm or regional characteristics that might affect firm survival. The size of a firm may have a positive impact on firm survival. However, no direct information on the size of the firm, as for example the number of employees or yearly turnover, is deducible from the data source. Alternatively, the size of the firm can be deduced from the total number of persons with signature right. It can be assumed, that larger firms delegate the signature right to more persons in comparison to smaller firms, as the top management has to delegate more tasks to lower management levels. Based on the size of management active in a firm, a dummy variable (with 1 for larger firms, 0 otherwise) was constructed ${ }^{10}$. Fixed effects variables for municipality and industry ${ }^{11}$ are also included in the regression models. A variable controlling for the formal education of the founder could not be included to limitations of the dataset. However, formal education seems to play a less important role for entrepreneurs in the periphery (Brouder and Eriksson 2012; Lööf and Nabavi 2014). Appendix A summarizes the descriptions of employed variables, appendix B shows descriptive statistics and correlations.

\section{Results}

First, the question is discussed if the case study regions are indeed characterized by limited clustering dynamics and limited but positive localization effects (Hypothesis 1). Dembinski, Schoenenberger, and Bologna (2008) statistically analysed clusters in Switzerland and identified several clusters where the case study regions contribute to, but no cluster is completely confined to either of the case study regions. Also, the contributions of the case 
study regions (in terms of employment) to the respective clusters they are attributed to are rather small ${ }^{12}$. However, this does not mean that localization effects are not existent at all. Model 1 (see Table 2) investigates the question whether the size of a local industry (Industry size) has a positive effect on the survival of firms. Beside the industry size variable, the share of medium-sized and large firms in the industry is also taken into account. Further, dummy variables for municipality and (4-digit) industry are added to the models. The size of an industry shows a small negative effect on firm hazard, indicating that firms might profit from a large local firm population in their industry. The share of medium-sized and large companies has no significant effect. Thus, hypothesis 1 can be accepted concerning the effect of industry size on firm survival.

In model 2, the pre-entry experience of entrants is taken into account. The type of entry is differentiated between de novo entrants (de_novo, reference category for all other types of entry), diversifiers (diversifier), experienced entrepreneurs (experienced) and spinoffs (spinoff). The results on the impact of pre-entry experience on firm survival are quite in line with the findings of previous heritage studies: Diversifying entrants and spinoffs show a lower hazard ratios when compared to de novo entrants. The relatively low hazard ratio of diversifiers seems reasonable, as both industrial and spatial diversifiers can rely on already established competences and routines. The lower level of local competition and lower costs for land and labour in peripheral areas might also give them more time to adapt to the new environment. This supports the assumption that a location in peripheral areas is advantageous for branch plants of manufacturing firms (Shaver and Flyer 2000). Spinoffs show a higher survival probability compared to de novo entrants, which speaks for the assumption that these firm inherit industry specific local competences and routines, giving them better starting conditions and thus raising their chances of survival. Thus, hypotheses 2 , stating that spinoffs show a higher survival chance in comparison to de novo entrants can be accepted. The insignificant results for experienced entrepreneurs prohibits any robust conclusions concerning their higher survival chance in comparison to de novo entrants.

From model 3 on, entry types are further differentiated in order to account for the characteristics of parent firms from experienced entrepreneurs and spinoffs. In model 3 experienced entrepreneurs and spinoffs are differentiated based on whether the founders gathered experience at a surviving firm, or no surviving firm, respectively. The coefficients for experienced entrepreneurs remain insignificant, prohibiting any further interpretations. For spinoffs, having experience from a surviving firm reduces the hazard ratio, and thus is in line with hypothesis 3 .

[Insert Table 2 around here]

In model 4, experienced entrepreneurs and spinoffs are differentiated whether they gathered experience at a medium-sized or large firm, or a small firm, respectively. Interestingly, the results are contrary to what was formulated in hypothesis 4: Spinoffs show a higher hazard ratio when they have a larger parent in comparison to spinoffs who have only gathered experience at small sized parents. Still, all types of spinoffs show lower hazard ratios in comparison to the reference group of de novo entrants. Thus, surviving parents may supposedly have a negative effect on the survival chance of new firms in peripheral areas, but 
having industry-specific pre-entry experience is still beneficial for survival. For experienced entrepreneurs, the results remain insignificant.

Starting from model 5 in Table 3, the two case study regions (Toggenburg and Rheintal) are compared in order to explore if heritage effects differ between the regions. When it comes to the heritage effects, the results differ between the two regions in several respects. First, the coefficient for spinoffs is smaller than one, and in all but two cases significant in both regions, again supporting the assumption that the higher survival chances of spinoffs is a phenomenon that is relevant across industries and regions. Yet, also sharp differences between the two regional firm populations become visible. The coefficients for industry size are below one both in the Toggenburg and the Rheintal as expected. There is thus no large difference between out- and underperforming regions concerning the positive effect of more local firms of the same industry.

\section{[Insert Table 3 around here]}

The results concerning differing effects in both regions concerning parent survival and parent size also reveal surprising results. The results concerning parent survival for spinoffs show the expected tendency. While the coefficients for spinoffs without a surviving parent are quite similar, the coefficient decreases more strongly in the Toggenburg for spinoffs with a surviving parent. Thus, the coefficient for the Toggenburg suggest that having experience from a surviving parent has a stronger positive impact on firm survival than in the Rheintal, supporting hypothesis 5 .

The results for the effect of larger parents on firm survival are somewhat surprising. For the Rheintal, the coefficients suggest that having a larger parent has a positive effect, although the result for spinoffs without larger parents is not significant. For the Toggenburg, the results suggest the opposite. Spinoffs without larger parents show a strongly decreased hazard ratio, both in comparison to spinoffs with larger parents in the same region (although not significant), and to spinoffs in the Rheintal. Consequently, hypothesis 6 has to be rejected.

The effects of having a larger parent in general, and the diverging effects between the Toggenburg and the Rheintal might be linked to parent hostility (Walter, Heinrichs, and Walter 2014). While a potentially hostile attitude of larger parents to their spinoffs is a known phenomenon (Klepper 2011), the specificity of peripheral areas might lie in the stronger influence these firms ultimately have (Arbuthnott et al. 2011). The limited size of local markets and the influence of managers and owners of large companies on a wide variety of local actors might explain why spinoffs encounter more difficulties from their larger parents in the Toggenburg. In the Rheintal, where the industrial dynamics lead to better developed local markets, the socio-economic influence of larger companies and their management on spinoffs might be more limited. .

\section{Conclusion}

This paper indicates that spinoff effects also occur in peripheral regions and that the heritage approach can be applied to these kind of regions. The data shows that local spinoffs in peripheral regions have a higher survival chance across regions and industries. This is important in two respects: First, as firms of entrepreneurs with local pre-entry experience show a higher survival chance, successful routines are thus also present at firms in peripheral 
areas. Otherwise, local spinoffs would not show a significantly higher survival chance as compared to firms without this experience. Second, the fact that spinoffs locate near their parent organization is, at least partly, also true for peripheral areas. One could expect the opposite, namely that spinoffs move away from their region of origin, as they are better aware of the unfavourable economic framework in peripheral regions and have the pre-entry experience necessary to prevail in a more competitive environment of core regions. Yet, roughly every sixth new firm is a local spinoff, thus showing a certain location inertia. The results hint at the fact that regional entrepreneurial heritage and spinoff dynamics might be an important aspect of endogenous regional development, not just in urban regions, but also in their peripheral counterparts. This strategy for economic development of peripheral regions has largely been ignored so far.

However, if inheritance effects are also present in peripheral areas, the question remains why firm population dynamics differ so much between core and peripheral economies. Among many justified explanations, this study might add an additional one. The finding that spinoffs perform generally better, while simultaneously spinoffs with larger parents show an increased failure probability presents an ambivalent picture of firm population dynamics in peripheral areas. Especially in the manufacturing industries, one can assume that medium sized and large firms are the best training ground for latent entrepreneurs, and thus the most valuable ones for endogenous regional development in the context of routine diffusion via spinoffs. However, the results show that spinoffs do not seem to always profit from larger parents. This negative effect of larger parents on spinoffs might be one of the distinguishing features of spinoff dynamics in the periphery. Comparable to core regions and national averages (Andersson and Klepper 2013), spinoffs show a higher survival chance in comparison to de novo entrants, due to their pre-entry experience. Larger firms might identify the potential threat coming from these presumably more performing entrants and initialize suppressing actions in order to crowd the new competitor out of the market. Klepper already hinted at the fact that 'it is natural for parents to want to suppress spinoffs in any way possible' (Klepper 2011, 152). Walter et al. (2014) show various ways how parent firms might deteriorate the starting conditions of spinoffs, but also argue how spinoffs can react to the hostile actions in order to improve their position. The difference to core areas is that larger companies in peripheral areas might have more means to deteriorate starting conditions for these entrants, due to their dominant market position and influence on local actors. Arbuthnott et al. (2011) found specific evidence how rigid threat responses from established firms can hamper regional renewal in the periphery. While Arbuthnott et al. (2011) draw their results from a single industry case study, this study shows that the larger parents can be significantly unfavourable throughout different manufacturing branches. The fact that the negative effect of larger parents is specifically relevant in the more peripheral Toggenburg further supports this argument.

Further, the study emphasizes the heterogeneity of peripheral regions. Since 'there is no such thing as the typical rural economy' (North and Smallbone 2000a, 87), the specific impact of regional, industrial and institutional contexts on firm population dynamics and entrepreneurial agency should not be underestimated (Hassink and Klaerding 2012). In order to verify the above mentioned assumptions, to explore possible additional effects that might hamper 
spinoff dynamics, and to evaluate the motives and strategies of local actors, qualitative indepth studies of spinoff dynamics would prove highly useful.

The conclusion that inheritance effects also exist in peripheral areas raises the question to what extent these contribute to regional development. As already mentioned, regional entrepreneurial heritage as 'reservoir of competences' can be understood as an important potential for endogenous development, under the precondition that spinoff dynamics are functioning well. However, it is not possible with the employed dataset to directly link spinoff dynamics with firm competitiveness (such as employment or sales growth) and ultimately with regional development. Research linking pre-entry experience and firm performance to regional development could produce valuable insights how to strengthen policies for peripheral economic development. Different reaction from the parent company toward spinoffs adds another degree of complexity to the matter. It might be that supporting spinoff dynamics generally would lead to severe intra-regional competition, which could lead to negative results for the economic development of the region. This raises the question whether policies should focus on spinoff dynamics generally, or whether it should be differentiated between entrepreneurship (supporting the creation of independent spinoffs), intrapreneurship (supporting firminternal entrepreneurial culture), or corporate spinoffs (supporting the creation of new firms which remain dependent of their parent company) (Seward and Walsh 1996). Further, this study is limited in its explanatory power, as it only analyses the local pre-entry experience of managers, not of all employees. However, it is fair to assume that this category of employees are among the most important when it comes to routine inheritance. Nonetheless, having a more complete picture of labour mobility and entrepreneurial dynamics would add important insights to regional development.

Finally, two important aspects related to pre-entry experience and firm survival are not considered in this study. First, related variety and regional branching might play an important role for firm formation dynamics and the strength of regional entrepreneurial heritage (Frenken and Boschma 2007). This might partly explain the insignificant results for experienced entrepreneurs, as this study does not take into account, whether they come from a related or unrelated industry. Especially in peripheral regions, industrial branching and regional renewal are important, but difficult to achieve. Analysing in more detail, how spinoff dynamics might influence regional branching in the periphery might lead to important insights how to support regional renewal. Second, I cannot account for extra-regional pre-entry experience of entrepreneurs. Since extra-regional linkages seem to be especially relevant for firms in peripheral regions (Rodríguez-Pose and Fitjar 2013), extra-regional pre-entry experience of entrepreneurs might also have a specific impact on spinoff dynamics. Thus, studies evaluating both regional and extra-regional pre-entry experience might give further indication on the diverging effects of knowledge sources at different spatial scales on industrial clustering and regional development.

Despite these shortcomings, the results of this study contribute to the literature on spinoff dynamics by clearly showing that they also exist in peripheral areas. A peculiarity of spinoff dynamics in the periphery might consist in the specific response of larger parents to the thread coming from their spinoffs. The differences between different types of peripheral regions speak in favour of a more nuanced perspective on peripheral regional economies. 


\section{Notes}

${ }^{1}$ In Switzerland, five metropolitan regions exist: Zurich, Basel, Bern, Geneva-Lausanne, and the Swiss area of the Milan region (Schuler et al. 2005). See also figure 1.

${ }^{2}$ Especially Germany, Austria and Switzerland host many Hidden Champions, relatively unknown, but highly specialized SMEs who are world market leaders in a specific niche (Simon 2009). It is not unusual that these companies are located in small town and peripheral areas.

${ }^{3}$ The Population as of 2012 is roughly 75,000 for the Rheintal and 82,000 for the Toggenburg.

${ }^{4}$ In 2012, the Rheintal holds 678, the Toggenburg 582 manufacturing firms.

${ }^{5}$ All figures presented in this paragraph are based on data from the Statistical Service of the Kanton of St. Gallen (statistik.sg.ch/) and the National Statistics Office of Switzerland (bfs.admin.ch/).

${ }^{6}$ The entries in the Ragionenbuecher do not clearly distinguish between firm and establishment. Since this paper is focusing on the work experience entrepreneurs gather during their employment in local establishments, the distinction between firm and plant is not relevant in this context. I will thus refer to local establishments as firms, regardless if this is a single plant company, or a branch plant.

${ }^{7}$ The place of citizenship, or "Buergerort", is a specificity of Swiss citizenship. It is neither the place of birth, nor the place of residence, but the municipality from which an individual got his civil rights granted. Legally speaking, it is practically irrelevant today, but can be used for statistical purposes. ${ }^{8}$ Firms surviving after 2004 are treated as right-censored cases. For the empirical analysis, firms founded after 1999 were excluded in order to prevent that very young firms were classified as 'survived'. This would cause an overrepresentation of surviving firms founded between 2000 and 2004.

${ }^{9}$ The firms' branch affiliation is based on the Swiss General Classification of Economic Activities (NOGA), which is grounded on the NACE (rev. 2) classification. However, the raw data does not classify the firms following the NOGA code, but only contains a general description of the firm's main economic activity. Thus, the 2-digit and 4-digit industry classification was manually derived from the firm's business activity description.

${ }^{10} \mathrm{~A}$ firm is considered not small if it has more than three active managers. I controlled if the proxy variable shows high correlation with the actual size of the firm in the following way. I extracted the population of manufacturing firms of the case study regions as of June 2015 from the AMADEUS Database (http://www.bvdinfo.com) which contains information on the number of management persons as well as a firm size classification. Based on the number of management persons, a second size classification was constructed. When compared to the firm size classification of the AMADEUS database, $82 \%$ of the firms are classified correctly within the classification based on the number of management persons.

${ }^{11}$ The municipality where the firm is located is used as spatial fixed effects dummy. As Switzerland is a highly federalized state, the municipalities have some scope of action when it comes to supporting newly founded firms. Further, 4-digit industry dummies (Swiss NOGA Classification) are included, as it is widely recognized that differences between industries (such as technology intensity, market structure etc.) are important for explaining different entrepreneurial dynamics.

${ }^{12}$ The largest contribution to a clusters consists of 1,600 employees (roughly $30 \%$ of total employment in the cluster) from the Rheintal region to the plastics cluster of north-eastern Switzerland (Dembinski, Schoenenberger, and Bologna 2008). 


\section{References}

Acs, Zoltan J., and David Storey. 2004. "Introduction: Entrepreneurship and Economic Development." Regional Studies 38 (8) (November): 871-877.

Agarwal, Rajshree, Raj Echambadi, April M Franco, and Mb Sarkar. 2004. "Knowledge Transfer Through Inheritance: Spinout Generation, Development, and Survival." Academy of Management 47 (4): 501-522.

Anderson, Alistair R. 2000. "Paradox in the Periphery: An Entrepreneurial Reconstruction?" Entrepreneurship \& Regional Development 12 (2): 91-109.

Andersson, Martin, and Steven Klepper. 2013. "Characteristics and Performance of New Firms and Spinoffs in Sweden.” Industrial and Corporate Change 22 (1): 245-280.

Arbuthnott, Andrew, J. Eriksson, S. Thorgren, and J. Wincent. 2011. "Reduced Opportunities for Regional Renewal: The Role of Rigid Threat Responses among a Region's Established Firms." Entrepreneurship \& Regional Development 23 (7-8): 603-635.

Armington, Catherine, and Zoltan J. Acs. 2002. "The Determinants of Regional Variation in New Firm Formation.” Regional Studies 36 (1): 33-45.

Audretsch, David B., Oliver Falck, Maryann P. Feldman, and Stephan Heblich. 2012. "Local Entrepreneurship in Context." Regional Studies 46 (3) (March): 379-389.

Baumgartner, Daniel, Marco Pütz, and Irmi Seidl. 2013. "What Kind of Entrepreneurship Drives Regional Development in European Non-Core Regions? A Literature Review on Empirical Entrepreneurship Research.” European Planning Studies 21 (8): 1095-1127.

Benneworth, Paul. 2004. "In What Sense 'regional Development?': Entrepreneurship, Underdevelopment and Strong Tradition in the Periphery." Entrepreneurship \& Regional Development 16 (6): 439-458.

Beugelsdijk, Sjoerd. 2007. "Entrepreneurial Culture, Regional Innovativeness and Economic Growth." Journal of Evolutionary Economics 17 (2): 187-210.

Boschma, Ron. 2015. "Do Spinoff Dynamics or Agglomeration Externalities Drive Industry Clustering? A Reappraisal of Steven Klepper's Work." Industrial and Corporate Change 24 (4): 859-873.

Boschma, Ron, and Koen Frenken. 2006. "Why Is Economic Geography Not an Evolutionary Science? Towards an Evolutionary Economic Geography." Journal of Economic Geography 6 (3) (October 4): 273-302. doi:10.1093/jeg/lbi022.

Boschma, Ron, and Rik Wenting. 2007. "The Spatial Evolution of the British Automobile Industry: Does Location Matter?" Industrial and Corporate Change 16 (2): 213-238.

Brouder, Patrick, and Rikard H. Eriksson. 2012. "Staying Power: What Influences Micro-Firm Survival in Tourism?” Tourism Geographies: 1-20. doi:10.1080/14616688.2011.647326.

Buenstorf, Guido, and Steven Klepper. 2009. "Heritage and Agglomeration: The Akron Tyre Cluster Revisited." The Economic Journal 119 (April): 705-733.

_. 2010. "Why Does Entry Cluster Geographically? Evidence from the US Tire Industry." Journal of Urban Economics 68 (2): 103-114.

Buercher, Sandra, Antoine Habersetzer, and Heike Mayer. 2016. "Entrepreneurship in Peripheral Regions: A Relational Perspective.” In Geographies of Entrepreneurship, edited by Elizabeth Mack and Haifeng Qian, 143-164. New York: Routledge.

Cheyre, Cristobal, Jon Kowalski, and Francisco Veloso. 2015. "Spinoffs and the Ascension of Silicon Valley." Industrial and Corporate Change: 1-22. 
Dahl, Michael S., Chrisian Pedersen, and Bent Dalum. 2003. "Entry by Spinoff in a High-Tech Cluster." 3-11. DRUID Working Paper. Aalborg.

Dahl, Michael S., and Toke Reichstein. 2007. "Are You Experienced? Prior Experience and the Survival of New Organizations." Industry and Innovation 14 (5): 497-511.

Dahl, Michael S., and Olav Sorenson. 2012. "Home Sweet Home: Entrepreneurs' Location Choices and the Performance of Their Ventures." Management Science 58 (6): 1059-1071.

_. 2013. "The Who, Why, and How of Spinoffs." Industrial and Corporate Change 23 (3): 661688.

Dembinski, Paul, Alain Schoenenberger, and Claudio Bologna. 2008. "Cluster in Der Schweizer Wirtschaft: Statistische Und Politische Betrachtung." Geneva.

Essletzbichler, J., and D. L. Rigby. 2007. “Exploring Evolutionary Economic Geographies.” Journal of Economic Geography 7 (5): 549-571.

Freire-Gibb, Lucio Carlos, and Kristian Nielsen. 2010. "Geography and Entrepreneurial Profile - A Study of Rural and Urban Populations in Denmark." In DRUID Winter Conference 2010. Aalborg.

. 2014. "Entrepreneurship Within Urban and Rural Areas: Creative People and Social Networks." Regional Studies 48 (1): 139-153.

Frenken, Koen, and Ron Boschma. 2007. "A Theoretical Framework for Evolutionary Economic Geography: Industrial Dynamics and Urban Growth as a Branching Process." Journal of Economic Geography 7 (5): 635-649.

Frenken, Koen, Elena Cefis, and Erik Stam. 2015. "Industrial Dynamics and Clusters: A Survey." Regional Studies 49 (1): 10-27.

Fritsch, Michael, and Pamela Mueller. 2004. "Effects of New Business Formation on Regional Development over Time.” Regional Studies 38 (8): 961-975.

Glaeser, Edward L., Stuart S. Rosenthal, and William C. Strange. 2010. "Urban Economics and Entrepreneurship.” Journal of Urban Economics 67 (1): 1-14.

Golman, Russell, and Steven Klepper. 2013. "Spinoffs and Clustering." 13.09. Papers in Evolutionary Economic Geography. Utrecht.

Hassink, Robert, and Claudia Klaerding. 2012. "Theoretical Advancements in Economic Geography by Engaged Pluralism." 12.02. Papers in Evolutionary Economic Geography. Utrecht.

Heebels, Barbara, and Ron Boschma. 2011. "Performing in Dutch Book Publishing 1880-2008: The Importance of Entrepreneurial Experience and the Amsterdam Cluster." Journal of Economic Geography 11 (6): 1007-1029.

Isaksen, Arne. 2015. "Industrial Development in Thin Regions: Trapped in Path Extension?" Journal of Economic Geography 15 (3): 585-600.

Klepper, Steven. 2001. "Employee Startups in High-Tech Industries." Industrial and Corporate Change 10 (3): 639-674.

- 2002. "The Capabilities of New Firms and the Evolution of the US Automobile Industry." Industrial and Corporate Change 11 (4): 645-666.

- 2007. "Disagreements, Spinoffs, and the Evolution of Detroit as the Capital of the U.S. Automobile Industry." Management Science 53 (4): 616-631.

_.2009. "Spinoffs: A Review and Synthesis." European Management Review 6 (3): 159-171.

. 2010. "The Origin and Growth of Industry Clusters: The Making of Silicon Valley and Detroit." Journal of Urban Economics 67: 15-32. 
2011. "Nano-Economics, Spinoffs, and the Wealth of Regions." Small Business Economics 37: $141-154$.

Lagendijk, Arnoud, and Anne Lorentzen. 2007. "Proximity, Knowledge and Innovation in Peripheral Regions. On the Intersection between Geographical and Organizational Proximity." European Planning Studies 15 (4): 457-466.

Lengauer, Lukas, and Franz Tödtling. 2010. "Regional Embeddedness and Corporate Regional Engagement: Evidence from Three Industries in the Austrian Region of Styria." In Conference Paper for the 8th European Urban \& Regional Studies Conference, 1-31.

Lööf, Hans, and Pardis Nabavi. 2014. "Survival, Productivity and Growth of New Ventures across Locations.” Small Business Economics 43: 477-491.

Malecki, Edward. 1994. "Entrepreneurship in Regional and Local Development." International Regional Science Review 16 (1-2): 119-153.

. 2003. "Digital Development in Rural Areas: Potentials and Pitfalls." Journal of Rural Studies 19: 201-214.

Martin, Ron, and Peter Sunley. 2015. "Towards a Developmental Turn in Evolutionary Economic Geography?” Regional Studies 49 (5): 712-732.

Maskell, Peter. 2001. "The Firm in Economic Geography.” Economic Geography 77 (4): 329-344.

Mayer, Heike. 2011. Entrepreneurship and Innovation in Second Tier Regions. Cheltenham: Edward Elgar.

Müller, Margrit. 2012. "Internationale Arbeitsverflechtung." In Wirtschaftsgeschichte Der Schweiz Im 20. Jahrhundert, edited by Patrick Halbeisen, Margrit Müller, and Beatrice Veyrassat, 339-465. Basel: Schwabe Verlag.

Nelson, Richard R., and Sidney G. Winter. 1982. An Evolutionary Theory of Economic Change. Cambridge, MA: Harvard University Press.

North, David, and David Smallbone. 2000a. "Innovative Activity in SMEs and Rural Economic Development: Some Evidence from England." European Planning Studies 8 (1): 87-106.

2000b. "The Innovativeness and Growth of Rural SMEs During the 1990s." Regional Studies 34 (2): 145-157.

Phillips, Damon J. 2002. "A Genealogical Approach to Organizational Life Chances: The ParentProgeny Transfer among Silicon Valley Law Firms, 1946-1996.” Administrative Science Quarterly 47 (3) (September): 474. doi:10.2307/3094848.

Renski, Henry. 2015. "Externalities or Experience? Localization Economies and Start-up Business Survival." Growth and Change 46 (3): 458-480.

Rigby, David, and Mark Brown. 2015. "Who Benefits from Agglomeration?” Regional Studies 49 (1): $28-43$.

Rodríguez-Pose, Andrés, and Rune Dahl Fitjar. 2013. "Buzz, Archipelago Economies and the Future of Intermediate and Peripheral Areas in a Spiky World." European Planning Studies 21 (3): 355372.

Schuler, Martin, Pierre Dessemontet, Dominique Joye, and Manfred Perlik. 2005. Die Raumgliederung Der Schweiz. Edited by Bundesamt für Statistik. Neuenburg.

Schumpeter, Joseph A. 1934. The Theory of Economic Development. London: Transaction Publishers.

Seward, James K, and James Walsh. 1996. "The Governance and Control of Voluntary Corporate Spin-Offs." Strategic Management Journal 17: 25-39.

Shane, Scott. 2003. A General Theory of Entrepreneurship: The Individual-Opportunity Nexus. Cheltenham: Edward Elgar. 
Shaver, Myles, and Fredrick Flyer. 2000. "Agglomeration Economies, Firm Heterogeneity, and Foreign Direct Investment in the United States." Strategic Management Journal 21: 1175-1193.

Simon, Herrmann. 2009. Hidden Champions of the Twenty-First Century: The Success Strategies of Unknown World Market Leaders. New York: Springer.

Sorenson, Olav, and Pino G. Audia. 2000. "The Social Structure of Entrepreneurial Activity : Geographic Concentration of Footwear Production in the United States ,." American Journal of Sociology 106 (2): 424-462.

Stephens, Heather, and Mark Partridge. 2011. "Do Entrepreneurs Enhance Economic Growth in Lagging Regions?" Growth and Change 42 (4): 431-465.

Stuart, Toby, and Olav Sorenson. 2003. "The Geography of Opportunity: Spatial Heterogeneity in Founding Rates and the Performance of Biotechnology Firms." Research Policy 32: 229-253.

Tödtling, Franz, and Michaela Trippl. 2005. "One Size Fits All? Towards a Differentiated Regional Innovation Policy Approach.” Research Policy 34 (8): 1203-1219. doi:10.1016/j.respol.2005.01.018.

Van Oort, Frank, Martijn Burger, Joris Knoben, and Otto Raspe. 2012. "Multilevel Approaches and the Firm-Agglomeration Ambiguity in Economic Growth Studies." Journal of Economic Surveys 26 (3): 468-491.

Walter, Sascha, Simon Heinrichs, and Achim Walter. 2014. "Parent Hostility and Spin-out Performance.” Academy of Management Journal 35: 2031-2042. doi:10.1002/smj.2201. 


\section{Tables}

\begin{tabular}{lrrrrrr}
\hline Firm type & Toggenburg & Percent & Rheintal & Percent & Total & Percent \\
\hline de novo & 261 & 66.08 & 324 & 60.22 & 585 & 62.70 \\
diversifier & 42 & 10.63 & 67 & 12.45 & 109 & 11.68 \\
experienced & 22 & 5.57 & 65 & 12.05 & 87 & 9.32 \\
spinoff & 70 & 17.72 & 82 & 15.24 & 152 & 16.29 \\
\hline experienced without surviving parent & 11 & 2.78 & 30 & 5.58 & 41 & 4.39 \\
experienced with surviving parent & 11 & 2.78 & 35 & 6.51 & 46 & 4.93 \\
spinoff without surviving parent & 49 & 12.41 & 45 & 8.36 & 94 & 10.08 \\
spinoff with surviving parent & 21 & 5.32 & 37 & 6.88 & 58 & 6.22 \\
\hline experienced without larger parent & 12 & 3.04 & 25 & 4.65 & 37 & 3.97 \\
experienced with larger parent & 10 & 2.53 & 40 & 7.43 & 50 & 5.36 \\
spinoff without larger parent & 26 & 6.58 & 37 & 6.88 & 63 & 6.75 \\
spinoff with larger parent & 44 & 11.14 & 45 & 8.36 & 89 & 9.54 \\
\hline
\end{tabular}

Table 1: Count and percent values for different entry types, differentiated by regions 
Model $1 \quad$ Model 2 Model $3 \quad$ Model 4

\begin{tabular}{|c|c|c|c|c|}
\hline Industry size & $\begin{array}{l}0.986^{* * *} \\
(0.004)\end{array}$ & $\begin{array}{l}0.988 * * * \\
(0.004)\end{array}$ & $\begin{array}{l}0.988 * * * \\
(0.004)\end{array}$ & $\begin{array}{l}0.988 * * * \\
(0.004)\end{array}$ \\
\hline Share larger firms & $\begin{array}{l}1.002 \\
(0.178)\end{array}$ & $\begin{array}{l}1.006 \\
(0.018)\end{array}$ & $\begin{array}{l}1.005 \\
(0.018)\end{array}$ & $\begin{array}{l}1.005 \\
(0.015)\end{array}$ \\
\hline \multicolumn{5}{|l|}{ Entry type } \\
\hline diversifier & & $\begin{array}{l}0.342 * * * \\
(0.079)\end{array}$ & $\begin{array}{l}0.370 * * * \\
(0.084)\end{array}$ & $\begin{array}{l}0.340 * * * \\
(0.078)\end{array}$ \\
\hline experienced & & $\begin{array}{l}0.811 \\
(0.184)\end{array}$ & & \\
\hline spinoff & & $\begin{array}{l}0.483 * * * \\
(0.093)\end{array}$ & & \\
\hline experienced without surviving parent & & & $\begin{array}{l}0.847 \\
(0.243)\end{array}$ & \\
\hline experienced with surviving parent & & & $\begin{array}{l}0.758 \\
(0.250)\end{array}$ & \\
\hline spinoff without surviving parent & & & $\begin{array}{l}0.522 * * * \\
(0.120)\end{array}$ & \\
\hline spinoff with surviving parent & & & $\begin{array}{l}0.421 * * * \\
(0.131)\end{array}$ & \\
\hline experienced without larger parent & & & & $\begin{array}{l}1.122 \\
(0.356)\end{array}$ \\
\hline experienced with larger parent & & & & $\begin{array}{l}0.646 \\
(0.190)\end{array}$ \\
\hline spinoff without larger parent & & & & $\begin{array}{l}0.440 * * * \\
(0.129)\end{array}$ \\
\hline spinoff with larger parent & & & & $\begin{array}{l}0.510 * * * \\
(0.124)\end{array}$ \\
\hline Larger firm & $\begin{array}{l}0.949 \\
(0.203)\end{array}$ & $\begin{array}{l}1.007 \\
(0.219)\end{array}$ & $\begin{array}{l}1.017 \\
(0.222)\end{array}$ & $\begin{array}{l}0.995 \\
(0.217)\end{array}$ \\
\hline Industry dummy & yes & yes & yes & yes \\
\hline Municipality dummy & yes & yes & yes & yes \\
\hline $\mathrm{LR} \mathrm{Chi}^{2}$ & $223.16^{* * *}$ & $259.53 * * *$ & $259.95 * * *$ & $261.49 * * *$ \\
\hline Log likelihood & -2199.662 & -2181.449 & -2181.239 & -2180.470 \\
\hline Number of single firms & 933 & 933 & 933 & 933 \\
\hline Number of observations & 1867 & 1867 & 1867 & 1867 \\
\hline Number of failures & 349 & 349 & 349 & 349 \\
\hline $\begin{array}{r}* \\
* * \\
* * *\end{array}$ & $\begin{array}{l}\text { Significant a } \\
\text { Significant a } \\
\text { Significant a }\end{array}$ & $\begin{array}{l}\text { the } 0.10 \mathrm{lev} \\
\text { the } 0.05 \mathrm{lev} \\
\text { the } 0.01 \mathrm{lev}\end{array}$ & & \\
\hline
\end{tabular}


Model 5 Model $6 \quad$ Model 7 Model 8

Toggenb. Rheintal Toggenb. Rheintal

\begin{tabular}{|c|c|c|c|c|}
\hline Industry size & $\begin{array}{l}0.952 * * * \\
(0.004)\end{array}$ & $\begin{array}{l}0.989 \\
(0.008)\end{array}$ & $\begin{array}{l}0.951 * * * \\
(0.004)\end{array}$ & $\begin{array}{l}0.989 \\
(0.007)\end{array}$ \\
\hline Share larger firms & $\begin{array}{l}0.905 \\
(0.034)\end{array}$ & $\begin{array}{l}1.026 \\
(0.026)\end{array}$ & $\begin{array}{l}0.907 * * * \\
(0.035)\end{array}$ & $\begin{array}{l}1.026 \\
(0.026)\end{array}$ \\
\hline \multicolumn{5}{|l|}{ Entry type } \\
\hline diversifier & $\begin{array}{l}0.157^{* * * *} \\
(0.010)\end{array}$ & $\begin{array}{l}0.333 * * * \\
(0.099)\end{array}$ & $\begin{array}{l}0.153 * * * \\
(0.084)\end{array}$ & $\begin{array}{l}0.336 * * * \\
(0.099)\end{array}$ \\
\hline \multicolumn{5}{|l|}{ experienced } \\
\hline \multicolumn{5}{|l|}{ spinoff } \\
\hline experienced without surviving parent & $\begin{array}{l}1.904 \\
(1.268)\end{array}$ & $\begin{array}{l}0.666 \\
(0.236)\end{array}$ & & \\
\hline experienced with surviving parent & $\begin{array}{l}1.631 \\
(1.168)\end{array}$ & $\begin{array}{l}0.801 \\
(0.302)\end{array}$ & & \\
\hline spinoff without surviving parent & $\begin{array}{l}0.533^{*} \\
(0.204)\end{array}$ & $\begin{array}{l}0.524 * * \\
(0.169)\end{array}$ & & \\
\hline spinoff with surviving parent & $\begin{array}{l}0.399^{*} \\
(0.220)\end{array}$ & $\begin{array}{l}0.466^{*} \\
(0.188)\end{array}$ & & \\
\hline experienced without larger parent & & & $\begin{array}{l}3.627 * \\
(2.566)\end{array}$ & $\begin{array}{l}0.660 \\
(0.274)\end{array}$ \\
\hline experienced with larger parent & & & $\begin{array}{l}0.936 \\
(0.712)\end{array}$ & $\begin{array}{l}0.768 \\
(0.251)\end{array}$ \\
\hline spinoff without larger parent & & & $\begin{array}{l}0.216^{* *} \\
(0.138)\end{array}$ & $\begin{array}{l}0.573 \\
(0.204)\end{array}$ \\
\hline spinoff with larger parent & & & $\begin{array}{l}0.657 \\
(0.253)\end{array}$ & $\begin{array}{l}0.443^{* *} \\
(0.159)\end{array}$ \\
\hline Larger firm & $\begin{array}{l}1.347 \\
(0.203)\end{array}$ & $\begin{array}{l}0.854 \\
(0.260)\end{array}$ & $\begin{array}{l}1.318 \\
(0.486)\end{array}$ & $\begin{array}{l}0.887 \\
(0.271)\end{array}$ \\
\hline Industry dummy & yes & yes & yes & yes \\
\hline Municipality dummy & yes & yes & yes & yes \\
\hline LR Chi ${ }^{2}$ & $160.87 * * *$ & $193.63 * * *$ & $165.29 * * *$ & $193.81^{* * *}$ \\
\hline Log likelihood & -700.655 & -1199.109 & -698.445 & -199.012 \\
\hline Number of single firms & 395 & 538 & 395 & 538 \\
\hline Number of observations & 831 & 1036 & 831 & 1036 \\
\hline Number of failures & 135 & 214 & 135 & 214 \\
\hline
\end{tabular}

Table 3: Results of proportional hazard cox regression models reporting hazard ratios (standard errors in parentheses), differentiated by outperforming (Rheintal) and underperforming (Toggenburg) regions 


\section{Appendix A: Variable descriptions}

\begin{tabular}{|c|c|}
\hline Variable name & Description \\
\hline larger firm & $\begin{array}{l}\text { Bivariate variable for firm size, measured as the amount of persons } \\
\text { with signature right at the first observation. "Larger firm"=1, if the } \\
\text { firm has more than three persons with signature right. Concerning the } \\
\text { relationship between firm size and amount of persons with signature } \\
\text { right, see footnote } 10 \text {. }\end{array}$ \\
\hline Industry size & $\begin{array}{l}\text { Number of firms by industry (two-digit industry classification) and } \\
\text { region. }\end{array}$ \\
\hline Share larger firms & $\begin{array}{l}\text { Share (in percent) of firms with the characteristic "larger firm"=1, by } \\
\text { industry (two-digit industry classification) and region. }\end{array}$ \\
\hline de novo & $\begin{array}{l}\text { New firm having only founders without any prior regional managerial } \\
\text { experience. }\end{array}$ \\
\hline diversifier & $\begin{array}{l}\text { New firm entries with founding years prior to the first observation } \\
\text { period. These firms are consequently not termed as new firms, but as } \\
\text { diversifiers. }\end{array}$ \\
\hline experienced & $\begin{array}{l}\text { New firm without any founder with prior regional managerial } \\
\text { experience in the industry where the new firm is active in, but with at } \\
\text { least one founder with regional managerial experience in another } \\
\text { industry. }\end{array}$ \\
\hline spinoff & $\begin{array}{l}\text { New firm with at least one founder with prior regional managerial } \\
\text { experience in the industry where the new firm is active in. }\end{array}$ \\
\hline experienced without surv. parent & $\begin{array}{l}\text { Experienced entrant without any parent firm that survived until the } \\
\text { censoring year. }\end{array}$ \\
\hline experienced with surv. parent & $\begin{array}{l}\text { Experienced entrant with at least one parent firm that survived until the } \\
\text { censoring year. }\end{array}$ \\
\hline spinoff without surv. parent & Spinoff without any parent firm that survived until the censoring year. \\
\hline spinoff with surv. parent & $\begin{array}{l}\text { Spinoff with at least one parent firm that survived until the censoring } \\
\text { year. }\end{array}$ \\
\hline experienced without larger parent & $\begin{array}{l}\text { Experienced entrant without any parent firm with the characteristic } \\
\text { „larger firm“. }\end{array}$ \\
\hline experienced with larger parent & $\begin{array}{l}\text { Experienced entrant with at least one parent firm with the characteristic } \\
\text { „larger firm“. }\end{array}$ \\
\hline spinoff without larger parent & Spinoff without any parent firm with the characteristic „larger firm“. \\
\hline spinoff with larger parent & $\begin{array}{l}\text { Spinoff with at least one parent firm with the characteristic „larger } \\
\text { firm“. }\end{array}$ \\
\hline
\end{tabular}




\section{Appendix B: Descriptive statistics and correlation table}

\begin{tabular}{|c|c|c|c|c|c|c|c|c|c|c|c|c|c|c|c|c|c|c|c|c|}
\hline & \multirow[t]{2}{*}{$\mathrm{N}=1867$} & \multirow[t]{2}{*}{ Mean } & \multirow{2}{*}{$\begin{array}{l}\text { Std. } \\
\text { Dev. }\end{array}$} & \multirow[t]{2}{*}{ Min } & \multirow[t]{2}{*}{ Max } & \multicolumn{15}{|c|}{ correlations } \\
\hline & & & & & & 1 & 2 & 3 & 4 & 5 & 6 & 7 & 8 & 9 & 10 & 11 & 12 & 13 & 14 & 15 \\
\hline 1 & larger firm & 0.105 & 0.307 & 0 & 1 & 1 & & & & & & & & & & & & & & \\
\hline 2 & Industry size & 64.193 & 38.064 & 1 & 135 & -0.12 & 1 & & & & & & & & & & & & & \\
\hline 3 & share larger firms & 3.763 & 4.136 & 0 & 25 & 0.29 & -0.30 & 1 & & & & & & & & & & & & \\
\hline 4 & de novo & 0.648 & 0.478 & 0 & 1 & -0.18 & 0.09 & -0.11 & 1 & & & & & & & & & & & \\
\hline 5 & diversifier & 0.102 & 0.302 & 0 & 1 & 0.05 & -0.08 & 0.05 & -0.46 & 1 & & & & & & & & & & \\
\hline 6 & experienced & 0.087 & 0.282 & 0 & 1 & 0.06 & -0.11 & 0.07 & -0.42 & -0.10 & 1 & & & & & & & & & \\
\hline 7 & spinoff & 0.164 & 0.370 & 0 & 1 & 0.15 & 0.03 & 0.05 & -0.60 & -0.15 & -0.14 & 1 & & & & & & & & \\
\hline 8 & experienced without surv. parent & 0.044 & 0.206 & 0 & 1 & 0.04 & -0.10 & 0.05 & -0.29 & -0.07 & $\mathrm{x}$ & $\mathrm{x}$ & 1 & & & & & & & \\
\hline 9 & experienced with surv. parent & 0.042 & 0.201 & 0 & 1 & 0.04 & -0.06 & 0.05 & -0.28 & -0.07 & $\mathrm{x}$ & $\mathrm{x}$ & -0.05 & 1 & & & & & & \\
\hline 10 & spinoff without surv. parent & 0.103 & 0.304 & 0 & 1 & 0.08 & 0.07 & 0.04 & -0.46 & -0.11 & $\mathrm{x}$ & $\mathrm{x}$ & -0.07 & -0.07 & 1 & & & & & \\
\hline 11 & spinoff with surv. parent & 0.061 & 0.240 & 0 & 1 & 0.12 & -0.05 & 0.04 & -0.35 & -0.09 & $\mathrm{x}$ & $\mathrm{x}$ & -0.06 & -0.05 & -0.09 & 1 & & & & \\
\hline 12 & experienced without larger parent & 0.037 & 0.189 & 0 & 1 & 0.03 & -0.10 & 0.09 & -0.27 & -0.07 & $\mathrm{x}$ & $\mathrm{x}$ & $\mathrm{x}$ & $\mathrm{x}$ & $\mathrm{x}$ & $\mathrm{x}$ & 1 & & & \\
\hline 13 & experienced with larger parent & 0.050 & 0.218 & 0 & 1 & 0.05 & -0.06 & 0.02 & -0.31 & -0.08 & $\mathrm{x}$ & $\mathrm{x}$ & $\mathrm{x}$ & $\mathrm{x}$ & $\mathrm{x}$ & $\mathrm{x}$ & -0.04 & 1 & & \\
\hline 14 & spinoff without larger parent & 0.064 & 0.245 & 0 & 1 & 0.05 & 0.00 & 0.05 & -0.36 & -0.09 & $\mathrm{x}$ & $\mathrm{x}$ & $\mathrm{x}$ & $\mathrm{x}$ & $\mathrm{x}$ & $\mathrm{x}$ & -0.05 & -0.06 & 1 & \\
\hline 15 & spinoff with larger parent & 0.100 & 0.300 & 0 & 1 & 0.14 & 0.03 & 0.03 & -0.45 & -0.11 & $\mathrm{x}$ & $\mathrm{x}$ & $\mathrm{x}$ & $\mathrm{x}$ & $\mathrm{x}$ & $\mathrm{x}$ & -0.07 & -0.08 & -0.09 & 1 \\
\hline
\end{tabular}




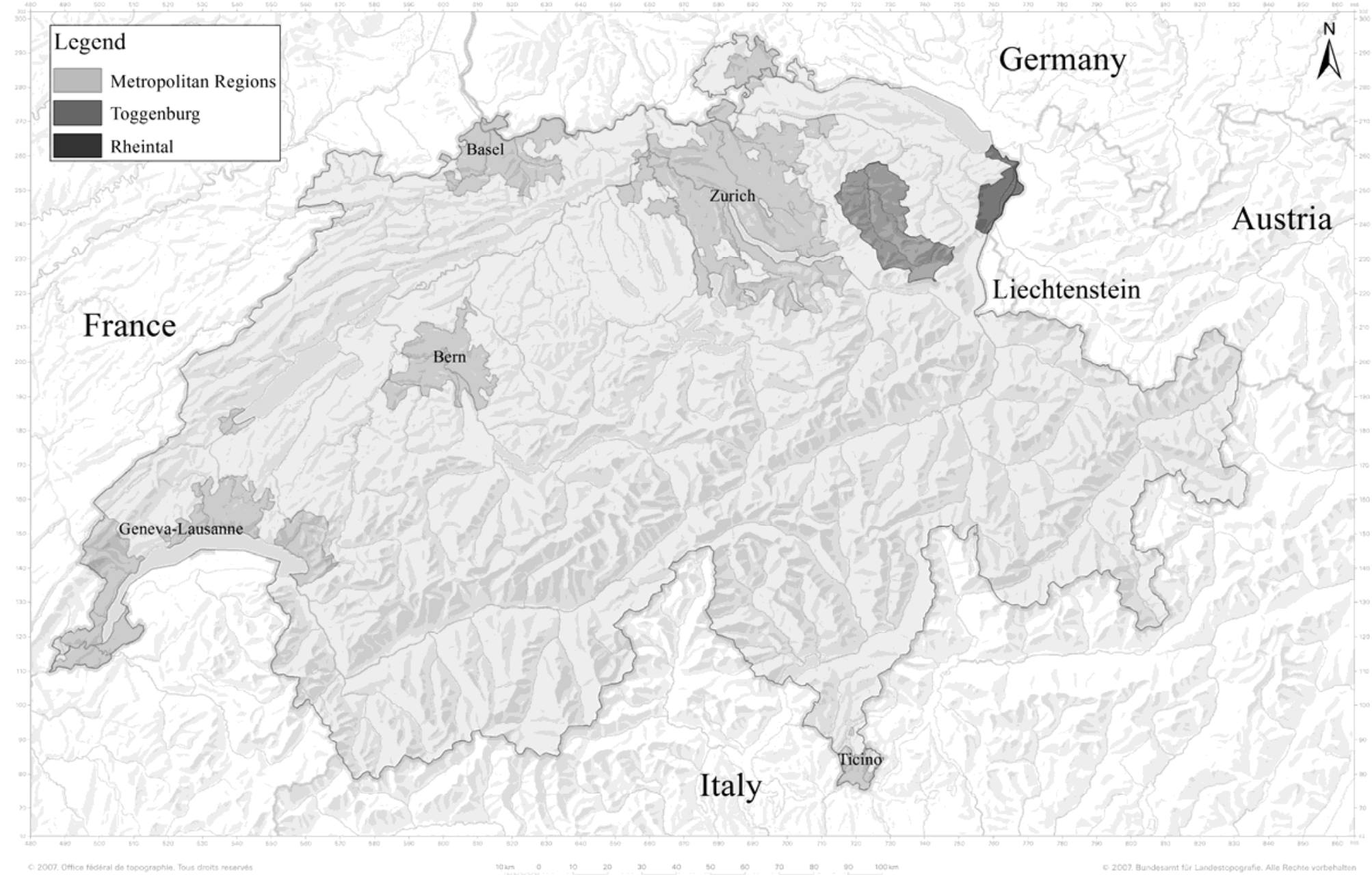

Figure 1: Case study regions and metropolitan regions in Switzerland. Source: Map base layer by the Swiss Federal Office of Topography, www.geo.admin.ch 